\title{
Experimental Unit
}

National Cancer Institute

\section{Source}

National Cancer Institute. Experimental Unit. NCI Thesaurus. Code C93388.

A physical entity which is the primary unit of interest in a specific research objective. In an interventional study, the experimental unit is assigned to an intervention. The experimental unit is also the unit of primary statistical analysis. Commonly the individual study subject (animal, person or product) is the experimental unit. Different experimental units must be capable of receiving different experimental interventions. 